\title{
Outer Root Sheath
}

National Cancer Institute

\section{Source}

National Cancer Institute. Outer Root Sheath. NCI Thesaurus. Code C62490.

An outer layer of stratified epithelium contiguous with the epidermis surrounding the hair follicle, which is thinnest at the level of the bulb and thickest in the middle portion of the hair follicle. 